\title{
Bladder autoaugmentation in adult patients with neurogenic voiding dysfunction
}

\author{
Manfred Stöhrer $^{1,2}$, Guus Kramer ${ }^{1}$, Mark Goepel ${ }^{2}$, Dieter Löchner-Ernst ${ }^{1}$, Dorothea Kruse ${ }^{1}$ and Herbert Rübben $^{2}$ \\ ${ }^{1}$ Department of Urology and Urodynamic Unit, BG Unfallklinik Murnau, Professor-Küntscher-Straße 8, D-82418 \\ Murnau; ${ }^{2}$ Department of Urology, University Hospital Essen, Hufelandstraße 55, D-45122 Essen, Germany
}

\begin{abstract}
Bladder autoaugmentation offers an alternative to enterocystoplasties for patients with low capacity high pressure bladders caused by non-malignant pathology. In particular for patients with neuropathic hyperreflexive bladders, refractory to less invasive therapy, bladder autoaugmentation will attain comparable results with less impact on life quality compared to other bladder augmentation procedures. The procedure does not preclude later enterocystoplasty or deafferentations. Over the last 7 years, 50 patients were treated by this method, some of them for other than neurogenic voiding dysfunction. Substantial increase of bladder capacity and compliance resulted, at the cost of increased residual urine and the need for intermittent catheterisation in most patients. Some patients are able to perform complete voiding at will. The time lapse between surgery and functional rehabilitation of the bladder (substantial increase of capacity and detrusor compliance) cannot be predicted yet. In most patients this amelioration was observed 1-6 months after surgery, but in some the effect was equivocal for a year or longer. Low-dose anticholinergics appear to speed up the therapeutic effect. One patient had enterocystoplasty and one deafferentation later, one had rupture of the bladder, probably from the use of an artificial sphincter, and two are rated as failures because of psychogenic bladder-centred problems. Bladder autoaugmentation is a favourable treatment for patients who are motivated to wait possibly longer for functional changes to occur and are willing to perform intermittent catheterisation afterwards.
\end{abstract}

Keywords: bladder autoaugmentation; neurogenic voiding dysfunction; detrusor compliance; quality of life

\section{Introduction}

For patients with neurogenic voiding dysfunction (NVD), surgical interventions on the lower urinary tract are indicated if conservative therapy does not lead to a balanced voiding. The range of surgical alternatives has grown vastly over the last decade. The techniques show a broadly differentiated scope and allow for an individualised therapeutic approach in most patients. This approach is not only determined by the clinical picture, but also by the patient's desires, particularly his quality of life.

A major urological problem in this category of patients is still the uncontrollable reflex bladder. ${ }^{1-3}$ For patients with this pathology the key issue is the filling phase. Because of the high tone of the bladder wall (low compliance bladder), the filling volume is small and high pressure is exerted almost permanently on the intramural ureter. This in turn leads to early deterioration of the upper urinary tract. High pressures during the voiding phase should not be neglected, but - because of their much shorter duration - have less impact on the upper urinary

Correspondence: M Stöhrer tract. The primary aim of treatment is thus revision of the low compliance condition. ${ }^{2,3}$ As a consequence, the patient's main subjective problems, infection and incontinence, will be treated concomitantly.

For treatment of male patients who are unable or unwilling to catheterise and accept to wear a condom urine collector to allow mobility, incision of the sphincter externus urethrae has proven its value., ${ }^{1,2,4}$ Long-term anticholinergic drug therapy is not always effective, since the patient's tolerance of side effects and compliance with the drug regimen may be reluctant. $^{5}$ In complete lesions, sacral root deafferentation may be considered. ${ }^{6}$ Unless a neurostimulator is implanted at the same time, ${ }^{7}$ the patient must be intermittently catheterised after this procedure. The implantation is particularly favourable for female tetraplegic patients.

Various enterocystoplastic procedures, final procedure for complete and incomplete spinal cord injured patients of both sexes, bear a high morbidity, are burdensome for the patient, and in the end constitute a relatively massive impairment of the quality of life..$^{3,8}$ The senior author (MS) introduced bladder autoaugmentation in the treatment of spinal cord injured 
patients in $1989 .^{9}$ This minor surgical procedure, changing the bladder in a relatively physiological way, shows comparable results and leaves the option open for later enterocystoplasty. The procedure is available for both complete and incomplete spinal cord lesions. Its aim is to produce a pressure sink by conversion of part of the bladder into a yielding section, mimicking a diverticulum. In this way, high filling pressure will be absorbed, compliance normalises, capacity increases and the patient will become continent. After this procedure, the majority of patients require to use a catheter, as is also the case after enterocystoplasty. The present results in 50 patients who underwent this procedure, demonstrate that these aims can be fulfilled.

Bladder autoaugmentation by partial excision of detrusor muscle was first published by Cartwright and Snow, ${ }^{10}$ also in children with congenital NVD. ${ }^{11}$ The basic intervention for all types of bladder autoaugmentation is to expose the intact mucosa by excision of part of the detrusor wall. Recently, variations of the technique have been published. ${ }^{9,12-25}$ The dissected detrusor wall can be used either partly ${ }^{10,11,21}$ or totally 24,25 for attachment of the bladder, partly ${ }^{10,11,21}$ or totally ${ }^{9,12,13}$ removed, or just deflected from the mucosa. ${ }^{14-19,23}$ Combinations with (demucosalised) enterocystoplasty or other coverage of the exposed mucosa are under study. ${ }^{14-19}$ Some groups perform bladder autoaugmentation as a laparascopic procedure. $^{23-25}$

Our decision to apply autoaugmentation was triggered by the observation that several NVD patients with hyperreflexive or low-compliant detrusors developed one single large diverticulum only instead of the usual multiple diverticulae (Figure 1a). Urodynamics in these patients demonstrated amelioration of their NVD condition: decreased detrusor pressure, increased capacity and improved detrusor

a

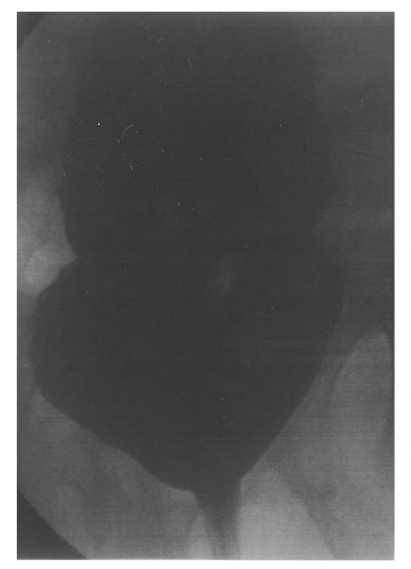

b

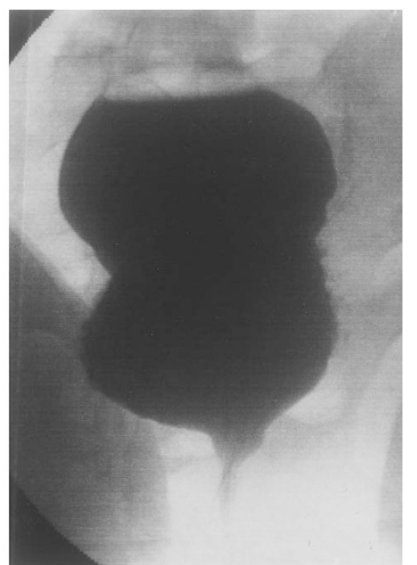

Figure 1 Large bladder diverticulae from disparate origin. (a) spontaneously (patient with neurogenic voiding dysfunction). (b) surgically created by bladder autoaugmentation (patient \#13) compliance related to the situation before the diverticulum, or compared with patients who did not develop this one large diverticulum. Moreover, their upper urinary tracts appeared to be less endangered.

Thus, it was conjectured that creation of a diverticulum by surgically removing part of the detrusor muscle might benefit this type of NVD patient (Figure 1b). This new option was proposed to patients who were eligible for enterocystoplasty because they were refractory to less invasive treatment. If this procedure should also fail, it would not complicate the planned enterocystoplasty.

\section{Methods and patients}

Surgery takes place under general anaesthesia. After introduction of a transurethral catheter, the bladder is exposed extraperitoneally and filled to anatomical capacity. Blue-dyed saline improves the view during the procedure. The peritoneum is dissected dorsally $(3-4 \mathrm{~cm})$ and the urachus taken in a holding clamp. Holding threads $(10-12)$ are placed around the urachus, confining $20-25 \%$ of the detrusor area, and knotted, occluding the blood vessels (Figure 2a). The detrusor muscle along the knots is carefully cauterised until the mucosa becomes visible. With anatomical scissors the frontocranial muscular part around the urachus is raised over an appropriate width and dissected off bluntly from the mucosa (Figure 2b). This part of the preparation demands prudence. After reaching the urachus from one side, invagination of the detrusor part to be excised soothes further preparation (Figure 2c). In trabeculated bladders it may be hard to remove every solitary muscle fibre, but this will not impair the therapeutic result (Figure 2d). Contrary to other groups, no filamentous detrusor bands are left, ${ }^{12}$ nor do we use detrusor flaps for fixation. ${ }^{10,11,21,24,25}$

The bladder is kept relatively slack during the dissection by regular partial drainage to prevent mucosal rupture, a not infrequent preoperative complication. ${ }^{9,11-13,18,21,23,25}$ Late sequelae are prevented by preoperative closing: clamping in a curved clamp and ligating with resorbable material (cf.). ${ }^{12,21}$. A Redon wound drain is left for 2 days. An indwelling urethral catheter is left for 2 days when no mucosal rupture occurred, otherwise for 1 week.

After removal of the indwelling catheter, intermittent catheterisation is initiated with about $3 \mathrm{~h}$ daytime and longer night-time intervals. A sufficient diverticulum did not develop in every patient spontaneously within a short term by the reflex bladder's hypercontractility. In some of them, the hyperreflexive detrusor postoperatively still caused high pressures. This was treated by anticholinergic drugs in a far lower than the (unsuccessful) preoperative dosage (cf.), ${ }^{20}$ resulting in many patients, particularly women, in complete continence between catheterisations.

After having observed lasting improvement for over one year after the first bladder autoaugmentation 


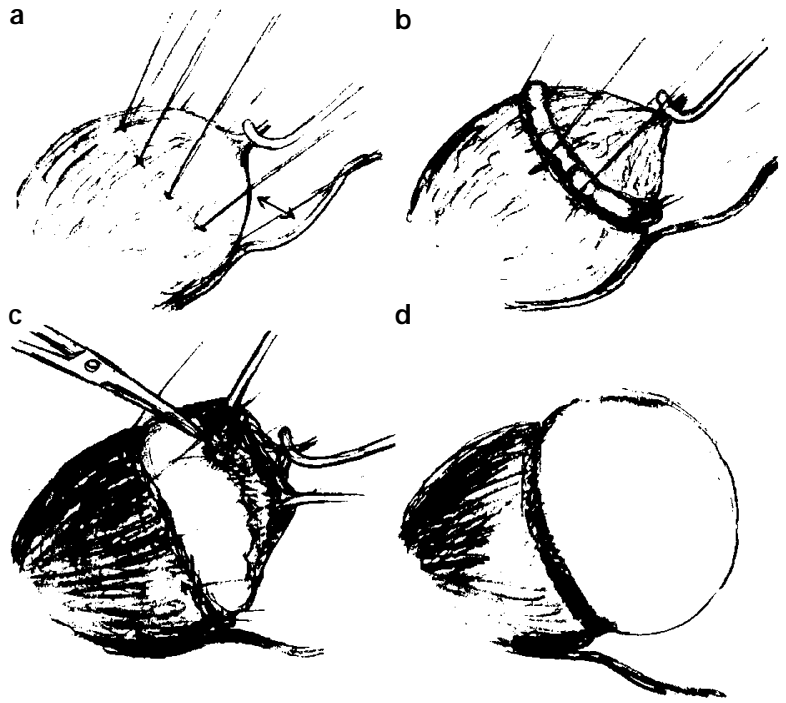

Figure 2 Technique for bladder autoaugmentation (side view): (a) situation after dissection of the peritoneum over $3-4 \mathrm{~cm}$ (holding clamp on the urachus), insertion of holding threads. (b) circular cauterisation, the detrusor muscle is bluntly dissected from the mucosa on one side up to the urachus. (c) preparation with invagination of the detrusor, bladder partially drained. (d) final situation

(1989) and 8-10 months after two more (1991/2), the method has been introduced in our clinic as an elective procedure for the treatment of high detrusor pressure during filling and/or decreased compliance since end 1992. Patients with other than NVD pathology causing this condition are also eligible.

Three urodynamic parameters (maximal cystometric capacity, detrusor compliance, maximal voiding pressure), X-ray videographic recordings and clinical findings are used to document the results. All pre- and postoperative videourodynamic studies were performed under the same conditions, adhering to the International Continence Society's standardisation rules. ${ }^{26}$ Body-warm contrast medium was slowly infused and the patient position was the same pre- and postoperatively. Table 1 lists the essential data of all 50 patients who have been treated to date.

\section{Results}

The first patient was a 38 year old male with spina bifida occulta and detrusor hyperreflexia. Maximum cystometric capacity was $180 \mathrm{ml}$; detrusor compliance $5 \mathrm{ml} / \mathrm{cm} \mathrm{H}_{2} \mathrm{O}$. During the filling phase detrusor pressures above $100 \mathrm{~cm} \mathrm{H}_{2} \mathrm{O}$ were noted due to the detrusor hyperreflexia. The patient was followed up closely during the year after surgery. After this year the high hyperreflexic pressures were no longer present, capacity had increased to $520 \mathrm{ml}$ and compliance to $40 \mathrm{ml} / \mathrm{cm} \mathrm{H}_{2} \mathrm{O}$. He was able to void normally, the voiding parameters had not changed from the pre- operative values: pressure $50 \mathrm{~cm} \mathrm{H}_{2} \mathrm{O}$, no residual. ${ }^{9}$ At the last follow-up visit, more than 6 years after surgery, his bladder condition was unchanged. Because of this positive result, two more patients were treated: a 34 year old male with paraplegia (Th2; incomplete) and a 41 year old male tetraplegic patient (C6/7, complete). Their results were also favourable: cystometric capacity $80 \rightarrow 400 \mathrm{ml}$ and $200 \rightarrow 600 \mathrm{ml}$; detrusor compliance $3 \rightarrow 30 \mathrm{ml} / \mathrm{cm} \mathrm{H} \mathrm{H}_{2} \mathrm{O}$ and $17 \rightarrow 50 \mathrm{ml} / \mathrm{cm} \mathrm{H}_{2} \mathrm{O}$, voiding pressure $60 \rightarrow 50 \mathrm{~cm}$ and $90 \rightarrow 50 \mathrm{~cm} \mathrm{H}_{2} \mathrm{O}$. The residual urine did not change essentially $(50 \rightarrow 35 \mathrm{ml} ; 0 \rightarrow 0 \mathrm{ml})$. Patient 2 has normal, patient 3 reflex voiding. ${ }^{9}$ Preexisting reflux in patient 2 disappeared spontaneously. ${ }^{9}$ In both patients the improvements lasted until their most recent follow-up visit (over 4 years). Voiding in these three patients is complete; the created diverticulum empties by recoiling during the contraction of the remaining part of the detrusor.

Preoperative mucosa perforation occurred in 23 patients. This was resolved by ligation over a curved clamp and no long-term detrimental effects have been encountered. Late complications of the procedure (longest follow-up 6 years and 8 months; 2 years or longer in 11 patients) were not seen. One bladder rupture occurred, probably from the obstructive effect of an artificial sphincter, implanted during the same session.

Five failures were observed. One man underwent deafferentation shortly after the autoaugmentation because of (pre-existing) considerable spasticity. One woman with an unclear cause for the uninhibited bladder had enterocystoplasty $1 \frac{1}{2}$ years after treatment although the results of the autoaugmentation were positive at 14 months follow-up. She desperately wanted to 'get rid of her bladder' and did not consult us any more. In two women, with suspected psychological problems, the follow-up results cannot be interpreted. The fifth case is a woman with rupture of the bladder 24 months after autoaugmentation. After Wertheim and irradiation the peritoneum was incomplete and the bladder was not separated from the abdominal cavity. She was considered as a 'highgrade incontinent patient' before surgery. Following the autoaugmentation, her urologist insisted on the implementation of a Scott sphincter immediately.

The final results are not available for all 50 patients; the follow-up of those who were treated relatively recently are still in progress. A minimum follow-up period of 6 months and a stable condition are required to certify a positive result; experience has taught us that in some patients a stable condition does not show before $1-2$ years.

Post-operative urodynamics are available for 36 of the patients; post-operative bladder capacity estimation for 38. Residual urine is estimated in only 22 patients who are not on intermittent catheterisation postoperatively. Pre- and postoperative results are statistically compared for 32 patients, significance was assessed by Wilcoxon's paired rank test at the $5 \%$ level. 
Table 1 Demographic data, diagnosis, date of surgery and follow-up

\begin{tabular}{|c|c|c|c|c|c|c|c|c|c|c|c|}
\hline Patient & Age & $\hat{0} / 9$ & Diagnosis & $\begin{array}{l}\text { Date of } \\
\text { surgery }\end{array}$ & $\begin{array}{l}\text { Follow up } \\
\text { (months) }\end{array}$ & Patient & Age & $0 / 9$ & Diagnosis & $\begin{array}{l}\text { Date of } \\
\text { surgery }\end{array}$ & $\begin{array}{l}\text { Follow up } \\
\text { (months) }\end{array}$ \\
\hline 1 & 33 & o & Spina bifida & $10 / 89$ & 80 & $25^{* 4}$ & 40 & o & Th4/5 complete & $1 / 94$ & 32 \\
\hline 2 & 34 & 0 & Th2 incomplete & $11 / 91$ & 50 & 26 & 35 & q & Th12 complete & $2 / 94$ & 17 \\
\hline \multirow[t]{2}{*}{3} & 41 & $\widehat{0}$ & C6/7 complete & $1 / 92$ & 49 & 27 & 41 & 우 & Th12 complete & $3 / 94$ & 6 \\
\hline & & & & & & $28 *^{5}$ & 21 & 우 & Unclear/low-cap & $4 / 94$ & 12 \\
\hline 4 & 27 & q & Spina bifida & 9/92 & 12 & & & & low-compl./psych? & & \\
\hline 5 & 36 & 우 & L1 incomplete & $10 / 92$ & 36 & 29 & 26 & 우 & Th6/7 complete & $1 / 94$ & 6 \\
\hline 6 & 69 & q & Interstitial cystitis & $10 / 92$ & 7 & 30 & 32 & 우 & Th3-5 complete & $2 / 95$ & 9 \\
\hline 7 & 17 & 우 & MMC & $11 / 92$ & 24 & 31 & 30 & 0 & Th9/10 complete & $2 / 95$ & 6 \\
\hline \multirow[t]{2}{*}{8} & 69 & o & Interstitial cystitis? & $11 / 92$ & 16 & 32 & 39 & 0 & Th8 complete & $2 / 95$ & 9 \\
\hline & & & & & & 33 & 52 & q & Gyn surg./low-cap. & $6 / 95$ & 6 \\
\hline 9 & 29 & o & MS & $11 / 92$ & 19 & & & & high-press./urge & & \\
\hline \multirow[t]{2}{*}{10} & 41 & $\hat{0}$ & Arachnoid cyst & $11 / 92$ & 28 & 34 & 26 & 우 & Th5/6 complete & $6 / 95$ & 6 \\
\hline & & & & & & 35 & 22 & $\widehat{0}$ & Surgery/radiation & $7 / 95$ & pending \\
\hline 11 & 30 & $\hat{\jmath}$ & Th6 complete & $12 / 92$ & 11 & & & & Ewing os sacrum & & \\
\hline \multirow[t]{2}{*}{12} & 32 & q & Myelitis & $1 / 93$ & 27 & 36 & 32 & 0 & Th5/6 complete & $7 / 95$ & \\
\hline & & & & & & 37 & 39 & q & Herniated disc & $7 / 95$ & pending \\
\hline 13 & 23 & 우 & MS & $3 / 93$ & 31 & & & & surgery & & \\
\hline 14 & 18 & 0 & Spina bifida & $4 / 93$ & 26 & 38 & 11 & 0 & Dysmelia & $8 / 95$ & 3 \\
\hline \multirow[t]{2}{*}{15} & 42 & q & Dermoid cyst/ & $4 / 93$ & 6 & 39 & 64 & 0 & Th9 incomplete & $9 / 95$ & pending \\
\hline & & & Conus medullaris & & & 40 & 24 & o & Th10 complete & $10 / 95$ & pending \\
\hline \multirow[t]{2}{*}{16} & 26 & 우 & Unclear/uninhibited & $5 / 93$ & 6 & 41 & 37 & 우 & Th1 complete & $1 / 96$ & pending \\
\hline & & & bladder & & & 42 & 20 & q & Spina bifida & $2 / 96$ & 2 weeks \\
\hline 17 & 31 & $\hat{0}$ & Th11 incomplete & $5 / 93$ & 9 & 43 & 24 & $\hat{0}$ & Th5/6 complete & $2 / 96$ & 2 weeks \\
\hline 18 & 26 & 우 & Spina bifida & $7 / 93$ & 18 & 44 & 46 & o & Sacrum aplasia, & $3 / 96$ & pending \\
\hline \multirow[t]{2}{*}{19} & 55 & 우 & Contusio cerebri, & $7 / 93$ & 24 & & & & failed rhizotomy & & \\
\hline & & & haemiplegic & & & 45 & 40 & $\hat{0}$ & Th12 complete & $4 / 96$ & 3 \\
\hline 20 & 36 & $\hat{\jmath}$ & Myelitis & $9 / 93$ & 13 & 46 & 52 & o & Th4 complete & $4 / 96$ & pending \\
\hline 21 & 14 & q & MMC & $10 / 93$ & 6 & 47 & 75 & q & Exulcerating & $5 / 96$ & 4 \\
\hline \multirow[t]{2}{*}{$22^{* 1}$} & 49 & 우 & Wertheim/radiation & $12 / 93$ & 16 & & & & interstitial cystitis & & \\
\hline & & & Bladder rupture & & 24 & 48 & 60 & $\hat{0}$ & Th8 complete & $5 / 96$ & 3 weeks \\
\hline $23^{* 2}$ & 41 & 우 & $\begin{array}{l}\text { Epilepsia/incompl. } \\
\text { spinal contusion }\end{array}$ & $12 / 93$ & 24 & 49 & 25 & q & Th12/L1 complete & $7 / 94$ & 24 \\
\hline $24 *^{3}$ & 40 & q & $\begin{array}{c}\text { Unclear/uninhibited } \\
\text { bladder/psych? }\end{array}$ & $1 / 94$ & 14 & 50 & 36 & $\hat{0}$ & Low compliance & $10 / 96$ & pending \\
\hline
\end{tabular}

*: Failures; ${ }^{1}$ Rupture; ${ }^{2}$ Psychological problems; ${ }^{3}$ Enterocystoplasty; ${ }^{4}$ Deafferentation; ${ }^{5}$ Psychological problems

For patients with at least 6 months follow-up, the maximal cystometric capacity increased from $121 \mathrm{ml}$ to $406 \mathrm{ml}(n=31, P=0.0000$; Figure 3$)$ and detrusor compliance from $6.1 \mathrm{ml} / \mathrm{cm} \mathrm{H}_{2} \mathrm{O}$ to $29.3 \mathrm{ml} / \mathrm{cm} \mathrm{H}_{2} \mathrm{O}$ $(n=32, \quad P=0.0000$; Figure 4). Maximal voiding pressure decreased from 86.4 to $50.9 \mathrm{~cm} \mathrm{H}_{2} \mathrm{O}(n=32$, $P=0.0000)$ and residual urine increased from 20 to $76 \mathrm{ml}(n=17, P=0.0214)$.

Compliance $\left(12-62 \mathrm{ml} / \mathrm{cm} \quad \mathrm{H}_{2} \mathrm{O}\right)$ and capacity $(200-600 \mathrm{ml})$ increased substantially in nearly all patients, but in the early post-operative phase hyperreflexic contractions must be suppressed sometimes by a transient low-dosage anticholinergic treatment. Either the diverticulum effectively reduces the pressure caused by enduring hyperreflexic contractions or the remaining detrusor part loses its hyperreflexia in the course of time. As expected, the residual urine increases in most patients. About 60\% require intermittent catheterisation after the procedure, usually starting immediately postoperative. The residual urine in the others is $0-340 \mathrm{ml}$. Surprisingly however, some patients void without any residual urine.

With the exception of the five failures, all patients have substantially improved, both subjectively and objectively (Figures 5 and 6). Pre-operative reflux was present in eight patients and disappeared spontaneously in five, reduced spontaneously in one from both sides to one ureter only and in one other patient one-sided reflux persists. Subjectively, 22 patients rated 'very good', 10 'good' and four 'improved'. Two patients had surgery very recently, and seven have not yet reached a stable condition, but are improving.

The first patient with bladder autoaugmentation (October 1989) had his last follow-up examination in August 1996. The bladder function was not impaired and in particular there was no reduction of capacity by fibrosis of the mucosa, which has been conjectured as a potential risk of this procedure. In none of our patients to date has mucosal fibrosis been observed. 
Bladder capacity

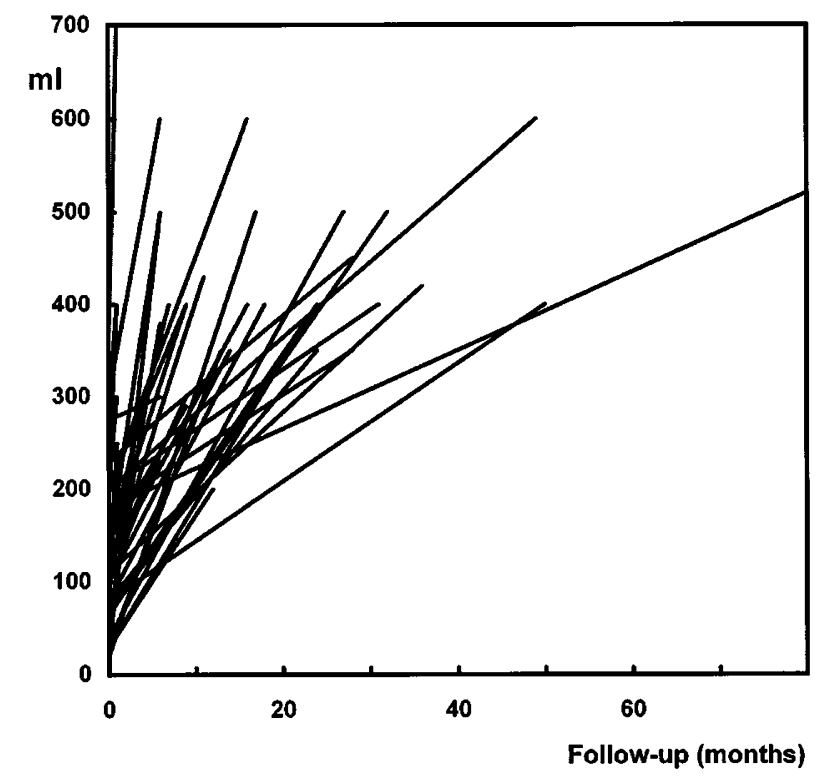

Figure 3 Preoperative data and data at last follow-up on maximal capacity for 37 patients. Follow-up durations between 2 weeks and 80 months

\section{Detrusor compliance}

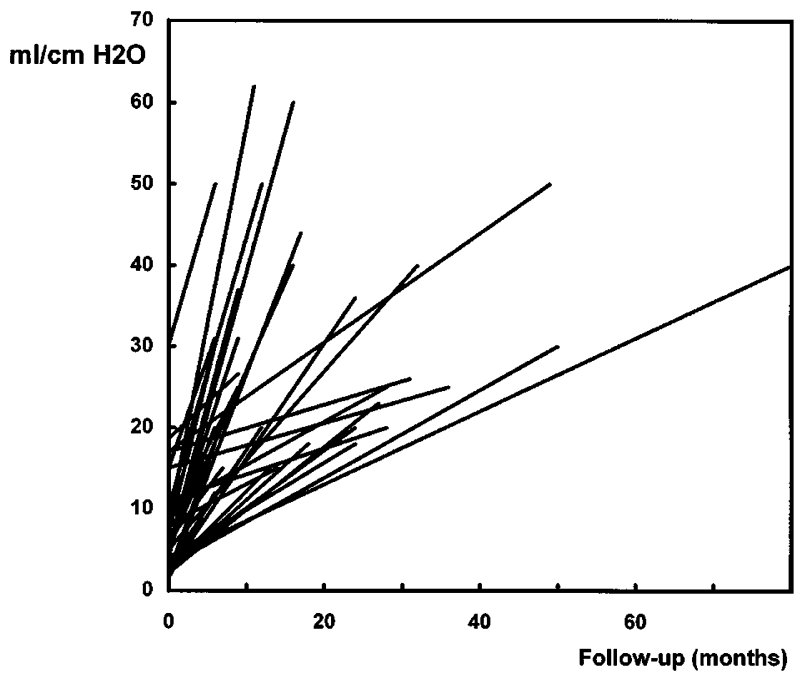

Figure 4 Preoperative data and data at the last follow-up on detrusor compliance for 34 patients. Follow-up durations between 3 and 70 months

\section{Discussion}

Enterocystoplasties for bladder substitution or augmentation in patients with bladder tumours showed good results. The technique is also employed for functional voiding dysfunctions. ${ }^{8}$ With malignant changes in the bladder wall there is no way around

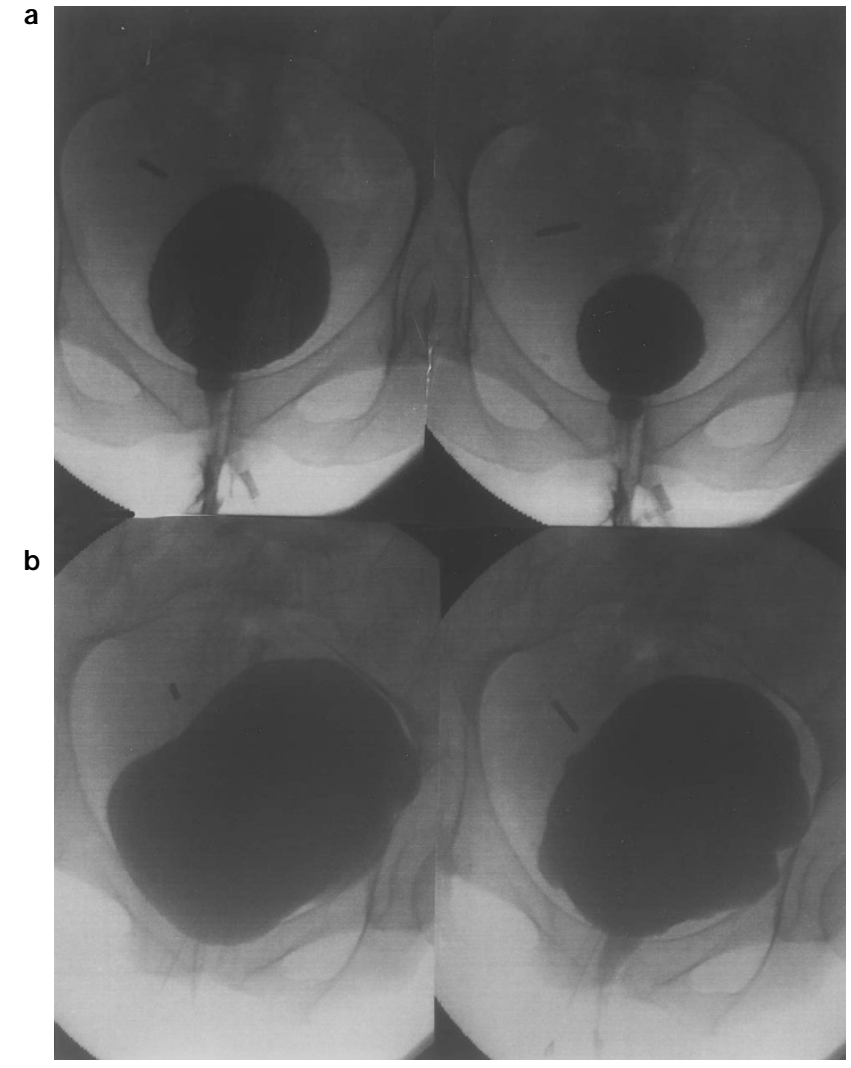

Figure 5 Patient \#34, female, 52 years, complete spinal cord lesion Th5/6. (a) pre-operative clear detrusor hyperreflexia with detrusor sphincter dyssynergia. (b) 5 months postoperative, distinct relaxation of the detrusor

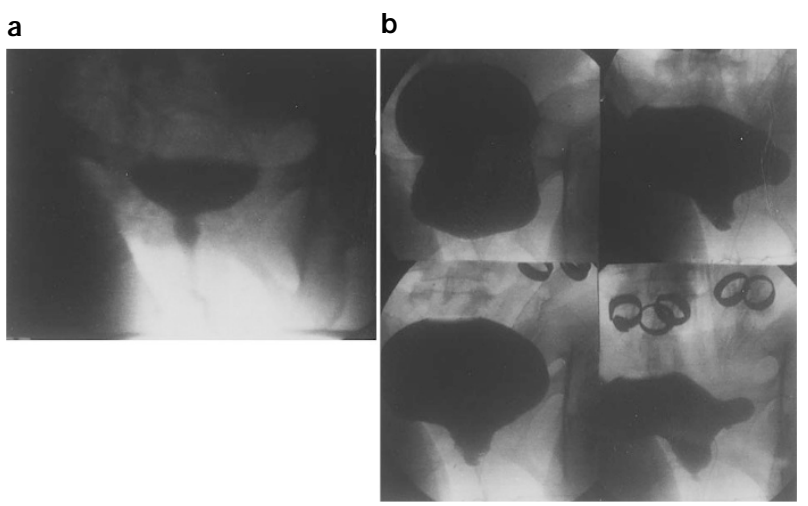

Figure 6 Patient \#12, female, 32 years, low-compliance reflex bladder after meningitis 1981. (a) pre-operative capacity $100 \mathrm{ml}$. (b) 27 months postoperative, capacity over $400 \mathrm{ml}$. By the end of the voiding phase the detrusor looks like a bladder neck, the diverticulum shows only small volume reduction

(partial) cystectomies, but for non-malignant voiding dysfunction it might be possible to prevent the adverse effects of enterocystoplasty by a more physiological approach. 
Cartwright and Snow, ${ }^{10}$ and Stöhrer ${ }^{13}$ observed the effects of a spontaneously developed single large diverticulum in some NVD patients with neurogenic high-pressure bladders ${ }^{2,9,13}$ or in patients with longstanding bladder outlet obstruction. ${ }^{10,11}$ They concluded that this more or less 'natural pressure sink' absorbed the high pressure, normalised compliance, and increased bladder capacity. This stimulated them to develop a surgical procedure to create such a diverticulum. This would improve bladder function, have low morbidity, omit the complications of intestinal substitution, save the options for further surgery, and improve the quality of life in NVD patients.

Contrary to many other groups, the present authors completely remove part of the detrusor wall, leaving the mucosa uncovered. The possibility of mucosal fibrosis, ${ }^{10,14-19,22,24}$ the reason for many groups to cover the mucosa after the dissection of the detrusor, was not confirmed in our patients over a follow-up period of up to 7 years. On urethrocystoscopy no manifest changes were observed. The resection rim was not clearly visible in some patients. In fact, the bulging capacity of the artificial diverticulum in most of our patients after 1-2 years (Figure 6) contradicts any possible fibrosis. Also, we did not observe any changes of the mucosa in our patients with a natural single wide-mouthed diverticulum, some of them consulting us for over 20 years. The incidence of urinary infections was greater in patients with multiple narrow-mouthed diverticula only and malignant changes occurred only in narrow-mouthed, chronically infected diverticula.

Covering the mucosa with grafts, ${ }^{14-19}$ causes morbidity in the donating organ, comparable to that for (partial) bladder substitution. The elasticity of the covered mucosa will be less and the risk of fibrosis appears to increase. ${ }^{16}$

Also, we do not see a need for fixation of the detrusor, eg to the ileopsoas ${ }^{10,11}$ or for leaving fibrous bands. ${ }^{12}$ In the first case the mobility of the remaining part of the detrusor will probably be impaired. In the second the yielding capacity of the mucosa will be less.

The advantage of partial detrusor myectomy instead of simple detrusor myotomy ${ }^{22-25}$ for bladder autoaugmentation is that regeneration of the muscular parts, covering the exposed mucosa will not take place easily. Also, the capacity increase after detrusor myotomy is smaller than after myectomy. No difference in capacity increase between the two techniques was found in rabbits, ${ }^{22}$ but in this study all animals developed mucosal fibrosis.

When the procedure is performed laparoscopically, possible mucosal perforation $9,12,13,18,21,23,25$ is more difficult to correct than in the open approach.

Long-lasting improvement of bladder compliance is confirmed by most authors who performed variants of autoaugmentation in patients, and capacity increase is also found, ${ }^{9-14}, 18,19,21,25$ but the lasting increase of capacity is questioned, ${ }^{10,27}$ particularly based on animal experiments. ${ }^{15,16,22}$ The reason may be found in technical variations, as discussed above, or in interspecies differences. No post-operative extravasation $^{11,23}$ has been noted, probably because we have full access to the mucosa and ligate any perforations immediately. Post-operative reflux de novo ${ }^{10}$ was not noted, but pre-operative reflux may improve spontaneously. ${ }^{9,10,12-14,18,19}$

Creation of the diverticulum by hypercontractility of the remaining section of the detrusor is obviously a very slow process. It may be accelerated by using lowdose anticholinergics, which were pre-operatively ineffective, to induce passive extension. Under such a regimen some of the younger female patients became continent immediately post-operatively. Post-operative balloon dilatation of the bladder ${ }^{25}$ has not been used by us.

Four patients with hypercontractile reflex bladders have spontaneous complete voiding post-operatively (cf.). ${ }^{11}$ Contraction of the remaining detrusor opens the bladder neck normally, voiding is effected at normal pressure and without residual urine.

The core philosophy in bladder autoaugmentation is to keep the procedure as simple as possible. It is not deemed by us that the technical variations found in literature improve the result beyond that after plain partial detrusor excision. The surgery time is $1 \frac{1}{2}-$ $2 \frac{1}{2} \mathrm{~h}$ and hospitalisation $2-6$ days, as is corroborated in the literature. ${ }^{10-12,20}$

Additional implantation of an artificial sphincter is problematic, ${ }^{18,21}$ even more so when the peritoneum is compromised after extensive pelvic surgery ${ }^{10}$ and/or radiation. Overflow incontinence, acting as a 'safety valve', is eliminated and thus bladder rupture may occur sooner. This is described for most ruptures after enterocystoplasty and resulted in bladder rupture also in one of our patients.

Two criteria are essential in patient selection. The patient must be motivated and understand that it may take a long time before bladder function has changed. In some patients, substantial increase of bladder capacity and continence were achieved within weeks, in others significant hyperreflexia lasted up to a year. Also, postoperative intermittent catheterisation is usually necessary. With enterocystoplasty as an alternative, however, this will also be the case. The patient should learn to perform intermittent catheterisation either herself or himself, or have it done by a third party.

\section{Conclusion}

Bladder autoaugmentation is in our view the therapy of choice before intestinal substitute surgery is considered for patients with low-capacity high pressure bladders who are refractory to less invasive therapy. By creation of an artificial diverticulum adequate bladder capacity and improvement of detrusor compliance are induced. The positive effects last for several years up till now. Secondary changes 
improved because of the lower bladder pressures during filling.

Bladder autoaugmentation is indicated in patients with non-malignant pathology, in majority NVD, causing reduced detrusor compliance and/or bladder capacity, who were otherwise scheduled for enterocystoplasty. It has a small morbidity and serious complications were not observed. More aggressive surgery, such as intestinal substitution, is not precluded (two failures in this study and ${ }^{11,19}$ ). Prerequisites for the procedure are the patient's capabilities to perform intermittent catheterisation and to understand that occasionally a longer period may pass to attain the striven functional changes. The indication for bladder autoaugmentation is broader than it is for electrostimulation, and also includes in particular NVD patients with incomplete lesions.

Application of bladder autoaugmentation is only significantly limited by the fact that most patients need intermittent catheterisation after the treatment. Lack of motivation from the patient is a relative contraindication; it partially explains the failures in our patient group (not a speedy success, psychosomatic affliction with bladder dysfunction). Two other failures were in patients with severe spasticity. The part of the detrusor excised may have been too small. Future intra-operative testing of the bladder response might prevent this kind of failure.

The best therapy for patients with pressure communication between the bladder and the upper urinary tract has not yet been discovered. In some, the reflux regressed completely after bladder autoaugmentation, in others this was not the case. In the latter patients, the growth of the created diverticulum took longer to develop, or is still unsatisfactory at present.

\section{References}

1 Stöhrer M. Alterations in the urinary tract after spinal cord injury - diagnosis, prevention and therapy of late sequelae. World J Urol 1990; 7: 205-211.

2 Stöhrer $\mathrm{M}$ et al. Diagnosis and treatment of bladder dysfunction in spinal cord injury patients. European Urology Update Series 1994; 3: $170-175$.

3 Rivas DA, Chancellor MB. Neurogenic vesical dysfunction. Urol Clin North Am 1995; 22: 579 - 591.

4 Selzman AA, Hampel N. Urologic complications of spinal cord injury. Urol Clin North Am 1993; 20: $453-464$.

5 Zeegers AGM, Kiesswetter H, Kramer AEJL, Jonas U. Conservative therapy of frequency, urgency and urge incontinence: a double-blind clinical trial of flavoxate hydrochloride, oxybutyinin chloride, emepronium bromide and placebo. World J Urol 1987; 5: 57-61.
6 Schneidau T, Franco I, Zebold K, Kaplan W. Selective sacral rhizotomy for the management of neurogenic bladders in spina bifida patients: long-term followup. J Urol 1995; 154: 766 - 768.

7 Wipfler G, Jünemann K-P. Funktionelle Wiederherstellung der Blasen funktion bei spastischer Querschnittslähmung mittels Elektrostimulation und sakraler Deafferentation. Aktuel Urol 1995; 26: $14-26$

8 Flood HD et al. Long-term results and complications using augmentation cystoplasty in reconstructive urology. Neurourol Urodyn 1995; 14: 297 - 309.

9 Stöhrer M et al. Bladder auto-augmentation - an alternative for enterocystoplasty: preliminary results. Neurourol Urodyn 1995; 14: $11-23$.

10 Cartwright PC, Snow BW. Bladder auto-augmentation: early clinical experience. J Urol 1989; 142: 505-508.

11 Cartwright PC, Snow BW. Bladder auto-augmentation: partial detrusor excision to augment the bladder without the use of bowel. J Urol 1989; 142: 1050-1053.

12 Kennelly MJ, Gormley EA, McGuire EJ. Early clinical experience with adult bladder auto-augmentation. J Urol 1994; 152: $303-306$.

13 Stöhrer M. Bladder auto-augmentation. In: Colleen S, Månsson $\mathrm{W}$ (eds). Reconstructive surgery of the lower genito-urinary tract in adults. Isis Medical Media: Oxford 1995, pp 32-40.

14 Dewan PA, Stefanek W. Autoaugmentation gastrocystoplasty: early clinical results. Br J Urol 1994; 74: 460-464.

15 Dewan PA, Lorenz C, Stefanek W, Byard RW. Urothelial lined colocystoplasty in a sheep model. Eur Urol 1994; 26: 240-246.

16 Dewan PA, Stefanek W, Lorenz C, Byard RW. Autoaugmentation omentocystoplasty in a sheep model. Urology 1994; 43: $888-$ 891.

17 Dewan PA et al. Autoaugmentation gastrocystoplasty and demucosalized gastrocystoplasty in a sheep model. Urology 1995; 45: $291-295$

18 Lima SV et al. Nonsecretory sigmoid cystoplasty: experimental and clinical results. J Urol 1995; 153: $1651-1654$.

19 Gonzalez R, Buson H, Reid C, Reinberg Y. Seromuscular colocystoplasty lined with urothelium: experience with 16 patients. Urology 1995; 45: $124-129$.

20 Labasky RF. Autoaugmentation (partial detrusor myomectomy) offers some advantages in adults with detrusor instability and incontinence. AUA Today 1996; 9(1): 6 .

21 Stothers L et al. Bladder autoaugmentation by vesicomyotomy in the pediatric neurogenic bladder. Urology 1994; 44: 110-113.

22 Johnson HW et al. Laboratory variables of bladder autoaugmentation in an animal model. Urology 1994; 44: 260-263.

23 Ehrlich RM, Gershman A. Laparoscopic seromyotomy (autoaugmentation) for non-neurogenic neurogenic bladder in a child: initial case report. Urology 1993; 42: 175-178.

24 Britanisky RG et al. Laparoscopic laser-assisted bladder autoaugmentation. Urology 1995; 46: $31-35$.

25 McDougall EM, Clayman RV, Figenshau RS, Pearle MS. Laparoscopic retropubic auto-augmentation of the bladder. $J$ Urol 1995; 153: 123 - 126.

26 Abrams P, Blaivas JG, Stanton SL, Andersen JT. Standardisation of terminology of lower urinary tract function. The International Continence Society Committee on Standardisation of Terminology. Neurourol Urodyn 1988; 7: 404-427.

27 Ehrlich RD. Editorial comment on ${ }^{24}$. Urology 1995; 46: 35. 